\title{
The connection of $\beta$-catenin and phenobarbital in murine hepatocarcinogenesis: a critical discussion of Awuah et al., PLoS ONE 7(6):e39771, 2012
}

\author{
Albert Braeuning \\ Received: 25 September 2012/Accepted: 17 December 2012/Published online: 25 December 2012 \\ (C) Springer-Verlag Berlin Heidelberg 2012
}

Phenobarbital (PB) is frequently used as a promoter of rodent liver tumors. The mechanisms by which PB exerts its tumorpromoting activity are still not fully understood, but the constitutive androstane receptor (CAR) and $\beta$-catenin seem to be essentially involved: Experiments with Car knockout (KO) mice have proven that the presence of CAR is mandatory for PB-mediated tumor promotion (Yamamoto et al. 2004). In mice, PB selects for the outgrowth of hepatocellular tumors with activating mutations in the Ctnnbl gene, which encodes the transcription factor $\beta$-catenin (Aydinlik et al. 2001). Similar observations were made with the PB-like tumor promoter PCB153 (Strathmann et al. 2006). Furthermore, $\mathrm{CAR}$ and $\beta$-catenin interact in the regulation of enzyme induction and hepatocyte proliferation triggered by $\mathrm{PB}$ (Braeuning et al. 2009; Braeuning et al. 2011).

In the absence of PB, two groups have studied hepatocarcinogenesis induced by diethylnitrosamine (DEN), a potent tumor initiator, in $\beta$-catenin-deficient livers from transgenic mice with conditional hepatocyte-specific $\mathrm{KO}$ of Ctnnb1. The unexpected finding of both studies was an increased number of tumors in Ctnnbl KO mice, which contradicts the classic view of $\beta$-catenin as an oncogenic driver of tumor formation (Rignall et al. 2011; Zhang et al. 2010). Possible explanations for this finding are increased inflammation and oxidative stress in the KO mice (Zhang et al. 2010), as well as the increased number of hepatocytes with high levels of $\mathrm{O}^{6}$-ethylguanine after $\mathrm{DEN}$ injection (Rignall et al. 2011). Subsequent administration of PB promoted tumor formation in livers of wild-type (WT)

\footnotetext{
A. Braeuning $(\square)$

Department of Toxicology, Institute of Experimental and Clinical Pharmacology and Toxicology, University of Tübingen, Wilhelmstr. 56, 72074 Tübingen, Germany e-mail: albert.braeuning@uni-tuebingen.de
}

$\mathrm{C} 3 \mathrm{H}$ mice, whereas a lack of tumor promotion was observed in Ctnnbl $\mathrm{KO}$ mice in the same experiment (Rignall et al. 2011). This can be attributed to the fact that the target cells of PB-mediated tumor promotion, namely Ctnnb1-mutated hepatoma cells, are largely absent from Ctnnb1 KO livers.

The group of Dr. Monga has recently reported an increase in liver tumor burden of DEN/PB-treated Ctnnb1 KO mice, as compared to WT controls (Awuah et al. 2012). This seemingly contradicts previous findings (Rignall et al. 2011) and thus questions the established connection of PB and $\beta$-catenin, at least for readers who are not highly specialized in the field of tumor promotion.

In their recent study, the authors treated 2-week-old C57BL/6 mice with a single dose of DEN, followed by chronic exposure to PB (Awuah et al. 2012). The age of mice at DEN injection is highly relevant since, in $\mathrm{C} 3 \mathrm{H}$ mice, it has been shown that PB inhibits hepatocarcinogenesis when the initiator DEN is given to 2-week-old mice, whereas it promotes tumorigenesis after DEN injection at 6 weeks of age (Moennikes et al. 2000). Comparably, PB inhibits tumor development in DENinduced ( 2 weeks) mice from strain $\mathrm{B} 6 \mathrm{C} 3 \mathrm{~F} 1$, a crossbreed of C3H and C57BL/6 (Diwan et al. 1984; Klaunig et al. 1987, 1988; Lee et al. 1998). The paradoxical phenomenon of tumor inhibition by $\mathrm{PB}$ has been reviewed by Lee (2000). Using CD1 mice, however, Tamano et al. (1994) have demonstrated tumor promotion by $\mathrm{PB}$ in animals treated with DEN at 2 weeks of age. Therefore, it cannot be excluded that $\mathrm{PB}$ has acted as a tumor promoter in the study by Awuah and colleagues. However, the majority of available studies argue against a tumor-promoting activity of PB when using the 2-week DEN treatment regimen, especially since the C57BL/6 strain is rather refractory to liver tumor formation and promotion (Maronpot 2009). 
Unfortunately, the study by Awuah et al. (2012) lacks the DEN-only control groups which could clarify whether tumor promotion has occurred in their study or not. Therefore, presented data do not allow the conclusion that PB has an impact on tumor development in Ctnnbl KO mice. Supposed that PB was inactive as a tumor promoter in their experiment, the result that Ctnnbl $\mathrm{KO}$ mice developed more tumors than their WT counterparts would be in accordance with previous results on non-PB-treated mice (Zhang et al. 2010; Rignall et al. 2011).

Indirect evidence for the above assumption that PB did not act as a tumor promoter in their study comes from the author's notion that the "utilized DEN/PB protocol in the WT C57BL/6 mice did not select for $\beta$-catenin gene mutations during hepatocarcinogenesis" (Awuah et al. 2012): PB and similarly acting compounds selectively promote the outgrowth of tumor cells with activated $\beta$-catenin in $\mathrm{C} 3 \mathrm{H}$ (Aydinlik et al. 2001), B6129SF2/J (Strathmann et al. 2006), and C57BL/6 mice (MarxStoelting et al. 2009; own unpublished analyses of tumors from the latter experiment). In addition, in Ctnnbl KO livers, chronic PB treatment provides a selective advantage to the few remnant $\beta$-catenin-possessing hepatocytes, as compared to surrounding Ctnnbl KO cells (Braeuning et al. 2010). It has also been shown that PB stimulates the growth of eosinophilic lesions while inhibiting the outgrowth of basophilic lesions in mouse liver (Lee 2000; Lee et al. 1998). Figure 1C of the paper by Awuah et al. (2012) shows a selection of liver lesions from their experiment which appear to be rather basophilic in nature.

In summary, the design of the latter study, lacking DENonly control groups, makes it impossible to decide whether or not PB has acted as a tumor promoter in the study by Monga's group. In view of the published literature cited above, it seems likely that PB had no promoting effect on tumorigenesis in the study by Awuah and colleagues. Therefore, the study does not necessarily conflict with previous results demonstrating an absence of PB-mediated tumor promotion in Ctnnbl KO mice (Rignall et al. 2011).

\section{References}

Awuah PK, Rhieu BH, Singh S, Misse A, Monga SP (2012) BetaCatenin loss in hepatocytes promotes hepatocellular cancer after diethylnitrosamine and phenobarbital administration to mice. PLoS ONE 7(6):e39771

Aydinlik H, Nguyen TD, Moennikes O, Buchmann A, Schwarz M (2001) Selective pressure during tumor promotion by phenobarbital leads to clonal outgrowth of beta-catenin-mutated mouse liver tumors. Oncogene 20(53):7812-7816

Braeuning A, Sanna R, Huelsken J, Schwarz M (2009) Inducibility of drug-metabolizing enzymes by xenobiotics in mice with liverspecific knockout of ctnnb1. Drug Metab Dispos 37:1138-1145
Braeuning A, Singh Y, Rignall B, Buchmann A, Hammad S, Othman A, von Recklinghausen I, Godoy P, Hoehme S, Drasdo D, Hengstler JG, Schwarz M (2010) Phenotype and growth behavior of residual beta-catenin-positive hepatocytes in livers of beta-catenin-deficient mice. Histochem Cell Biol 134(5): $469-481$

Braeuning A, Heubach Y, Knorpp T, Kowalik MA, Templin M, Columbano A, Schwarz M (2011) Gender-specific interplay of signaling through beta-catenin and CAR in the regulation of xenobiotic-induced hepatocyte proliferation. Toxicol Sci 123(1): $113-122$

Diwan BA, Rice JM, Ward JM, Ohshima M, Lynch PH (1984) Inhibition by phenobarbital and lack of effect of amobarbital on the development of liver tumors induced by N-nitrosodiethylamine in juvenile B6C3F1 mice. Cancer Lett 23(2):223-234

Klaunig JE, Weghorst CM, Pereira MA (1987) Effect of the age of B6C3F1 mice on phenobarbital promotion of diethylnitrosamine-initiated liver tumors. Toxicol Appl Pharmacol 90(1):7985

Klaunig JE, Weghorst CM, Pereira MA (1988) Effect of phenobarbital on diethylnitrosamine and dimethylnitrosamine induced hepatocellular tumors in male $\mathrm{B} 6 \mathrm{C} 3 \mathrm{~F} 1$ mice. Cancer Lett 42(1-2):133-139

Lee GH (2000) Paradoxical effects of phenobarbital on mouse hepatocarcinogenesis. Toxicol Pathol 28(2):215-225

Lee GH, Ooasa T, Osanai M (1998) Mechanism of the paradoxical, inhibitory effect of phenobarbital on hepatocarcinogenesis initiated in infant $\mathrm{B} 6 \mathrm{C} 3 \mathrm{~F} 1$ mice with diethylnitrosamine. Cancer Res 58(8):1665-1669

Maronpot RR (2009) Biological basis of differential susceptibility to hepatocarcinogenesis among mouse strains. J Toxicol Pathol 22(1):11-33

Marx-Stoelting P, Borowiak M, Knorpp T, Birchmeier C, Buchmann A, Schwarz M (2009) Hepatocarcinogenesis in mice with a conditional knockout of the hepatocyte growth factor receptor c-Met. Int J Cancer 124(8):1767-1772

Moennikes O, Buchmann A, Romualdi A, Ott T, Werringloer J, Willecke K, Schwarz M (2000) Lack of phenobarbital-mediated promotion of hepatocarcinogenesis in connexin32-null mice. Cancer Res 60(18):5087-5091

Rignall B, Braeuning A, Buchmann A, Schwarz M (2011) Tumor formation in liver of conditional beta-catenin-deficient mice exposed to a diethylnitrosamine/phenobarbital tumor promotion regimen. Carcinogenesis 32(1):52-57

Strathmann J, Schwarz M, Tharappel JC, Glauert HP, Spear BT, Robertson LW, Appel KE, Buchmann A (2006) PCB 153, a nondioxin-like tumor promoter, selects for $\beta$-catenin (Catnb) mutated mouse liver tumors. Toxicol Sci 93(1):34-40

Tamano S, Merlino GT, Ward JM (1994) Rapid development of hepatic tumors in transforming growth factor $\alpha$ transgenic mice associated with increased cell proliferation in precancerous hepatocellular lesions initiated by $\mathrm{N}$-nitrosodiethylamine and promoted by phenobarbital. Carcinogenesis 15:1791-1798

Yamamoto Y, Moore R, Goldsworthy TL, Negishi M, Maronpot RR (2004) The orphan nuclear receptor constitutive active/androstane receptor is essential for liver tumor promotion by phenobarbital in mice. Cancer Res 64(20):7197-7200

Zhang XF, Tan X, Zeng G, Misse A, Singh S, Kim Y, Klaunig JE, Monga SP (2010) Conditional beta-catenin loss in mice promotes chemical hepatocarcinogenesis: role of oxidative stress and platelet-derived growth factor receptor alpha/phosphoinositide 3-kinase signaling. Hepatology 52(3):954-965 